\title{
O QUE DIZEM OS ENFERMEIROS SOBRE OBSERVAÇÃO
}

Virginia Visconde Brasil*

BRASIL, V.V. O que dizem os enfermeiros sobre Observação. Rev.latino-am.enfermagem, Ribeirão Preto, v. 5, n. 3, p. 83-94, julho 1997.

Este estudo teve por objetivo caracterizar o que os enfermeiros docentes e assistenciais entendem por Observação na sua atuação profissional. Foram realizadas entrevistas com 11 profissionais, e para análise os dados foram agrupados em categorias. Foi possível identificar a importância que lhe atribuem, como instrumento essencial na administração da assistência de enfermagem, no levantamento de dados no planejamento das intervenções assim como na avaliação dos resultados.

UNITERMOS: observação, enfermagem, instrumento básico de enfermagem

A reflexão que se faz sobre "o agir" na Enfermagem, nos leva a uma série de questionamentos sobre como processá-lo. Muitas vezes "agimos" e não sabemos porque o fizemos. Fazemos de uma forma que "todos sempre fizeram", sem parar para refletir antes, e nem depois. Parece que não há uma sistematização, e provavelmente, se algo não sai como o esperado, dizemos que foi obra do acaso, sem uma reflexão consciente sobre o nosso agir profissional.

O caminhar da ciência, entretanto, não aceita mais este tipo de atitude, colocando de lado aqueles que não agem com o rigor que requer o agir profissional. Sob esta ótica, surge a necessidade do enfermeiro ter o conhecimento que the instrumentaliza a ação. A base de sua atuação encontra-se alicerçada no conhecimento do ambiente que o cerca, bem como no domínio de um saber científico próprio, direcionado para a sua atuação de forma organizada e sistematizada.

Neste contexto, surge a preocupação com o estabelecimento do instrumental necessário para o desempenho profissional - qual seria o conhecimento e as habilidades a serem desenvolvidas que capacitariam o indivíduo a agir com segurança?

No Brasil, HORTA ${ }^{8}$ os denominou de Instrumentos Básicos de Enfermagem, e dentre eles está a OBSERVAÇÃO. Esta autora coloca este instrumento na $1^{\text {a }}$ etapa do Processo de Enfermagem - Histórico, como recurso da coleta de dados, cujo objetivo principal é fornecer as premissas necessárias ao estabelecimento do Diagnóstico de Enfermagem.

A observação é uma capacidade não apenas humana, desde que o mundo é mundo. No cotidiano, é uma das formas mais usadas pelo homem para conhecer e compreender pessoas, coisas, acontecimentos e situações $^{15}$. É o meio básico de se conseguir informações. Ao verificarmos o tempo para decidir sobre o uso de um guarda-chuva, observarmos o trânsito para decidir quando atravessar uma rua, ou observarmos a atuação de um aluno e mesmo de um funcionário no trabalho, essa observação tem sentidos ou objetivos diferentes . Há porém, um ponto comum em todos esses momentos - é o ato de se obter informações para se tomar decisões, após o julgamento de uma situação.

A literatura sobre este assunto, principalmente na Enfermagem, não é extensa nos últimos anos. A maioria dos estudos datam das décadas de 70 e 80 como foi evidenciado também por DIAS ${ }^{5}$. Não são muitos os profissionais da área que estudaram o assunto e registraram seu pensamento. Há, entretanto, citações desde Nightingale no século passado, demonstrando sua preocupação com o treinamento do profissional - "A mais importante lição prática que pode ser dada aos enfermeiros é ensiná-los a observar - como observar que sintomas indicam melhoras - quais significam o inverso - quais são de importância - quais não o são quais são as evidências da falta de cuidados - e de que espécie de falta" $" 12$. Esta autora ressalta ainda a importância da observação no cuidar, mostrando a necessidade de se saber observar um paciente para ser um profissional: "o verdadeiro $\mathrm{ABC}$ de um enfermeiro é ser capaz de ler cada mudança que se opera na fisionomia do paciente, sem causar-lhe o esforço de dizer o que está

* Enfermeira, Professora da Faculdade de Enfermagem e Nutrição da Universidade Federal de Goiás. Mestranda da Escola de Enfermagem da Universidade de São Paulo 
sentindo (...) o profissional que nunca observa a fisionomia do paciente e nunca espera ver nela qualquer modificação, está a caminho do nada ; nunca será enfermeiro (....) não é o fato de encarar o doente que vai mostrar ao observador as pequenas coisas que deseja saber (....) apenas a observação confere experiência, mas o fato de se ter cuidado de doentes por anos não torna ninguém mais sábio (...) Sem o costume de observar de maneira rápida e atilada, nós enfermeiros seremos inúteis, mesmo com toda nossa abnegação".

Na opinião de SUNDBERG ${ }^{16}$, observar "é o ato ou prática de notar e registrar os fenômenos (fatos e eventos) (....) habilidade essencial usada para auxiliar na identificação de problemas físicos e emocionais, melhorada com treino e experiência (....) base do levantamento de dados".

Para HEGENBERG ${ }^{6}$, observar não é um "simples ver", mas um "ver prestando atenção, controlando, vigiando".

DIAS $^{5}$ acredita que as observações em enfermagem consistem em bem mais que elencar desvios óbvios nas condições dos pacientes. Em sua Dissertação de Mestrado evidenciou o uso equivocado do termo "observação" na literatura existente em Enfermagem no Brasil (de 1970 a 1986), dentro das áreas de atuação ensino, pesquisa e assistência. Buscou rever as concepções e as significações que são dadas à observação por autores enfermeiros. Ao final de seu estudo, sugeriu seu uso de maneira unívoca, visto que encontrou, dependendo do campo em que se encontrava o autor, concepções diferentes tais como - meio de coleta de dados, primeiro passo da investigação científica, técnica de coleta de dados, procedimento, habilidade, capacidade, instrumento básico de enfermagem, processo, papel, função, método e primeiro passo da assistência de enfermagem.

A leitura deste trabalho, durante estudo sobre os Instrumentos Básicos de Enfermagem preconizados por Horta, despertou a curiosidade sobre qual seria o significado da observação, no contexto profissional daqueles enfermeiros que não escreveram sobre o assunto, ou seja, aqueles profissionais que ainda não haviam feito uma reflexão mais aprofundada envolvendo a observação.

Como enfermeira assistencial e docente, foi possível constatar que a observação é essencial no ensino, pesquisa e assistência, assim como, que na Enfermagem, um dos termos mais usados é o "observar".

No dia-a-dia, ouvimos que, pelo fato do enfermeiro ser o profissional que maior tempo permanece ao lado dos pacientes, apresenta melhores condições para "observá-los" e documentar estas observações. Não há entretanto, uma maneira única de fazê-lo. O termo "observação" tem conotação ambígua, sendo utilizado às vezes, de maneira errônea pela subjetividade que a palavra impõe. Na realidade, talvez nenhum de nós tenha atentado para o que é observar, como e quando fazê-lo, com que objetivo observar e como adquirir essa habilidade.

Este estudo buscou então, explicitar o que pensam os enfermeiros sobre a observação; o que significa "observar" na atuação profissional daqueles que ainda não se detiveram em estudar e escrever sobre o tema.

\section{MATERIAL E MÉTODO}

Os dados foram colhidos em dois Hospitais e duas Escolas de Graduação em Enfermagem Públicos, situados no município de São Paulo, num total de 11 profissionais que atuavam na assistência e no ensino, no período de setembro a outubro de 1995

Os enfermeiros assistenciais entrevistados atuavam nas áreas médico-cirúrgica, terapia intensiva, pediatria e centro-cirúrgico; os docentes ministravam disciplinas nas áreas médico-cirúrgica, terapia intensiva, administração e fundamentos de enfermagem.

Foram realizadas entrevistas individuais, registradas com a técnica de gravador pela autora, sendo excluídos aqueles enfermeiros autores de algum estudo sobre observação.

A pergunta feita aos enfermeiros durante as entrevistas foi:

"Qual o significado da observação no seu contexto profissional?"

As entrevistas foram transcritas literalmente, seu conteúdo estudado e codificado em categorias.

Para tanto, buscou-se identificar sistemática e objetivamente a ocorrência de características manifestas nas falas dos entrevistados, sem perder de vista o objetivo do estudo ${ }^{1}$.

Dessa forma tentou-se, como sugere ROSEMBERG $^{14}$, categorizar partes de um discurso para desvendar significados, ou "identificar a melhor forma de tradução do objeto de estudo no material escolhido, isto é, o processo de intervenção na mensagem, para lhe definir uma nova organização que possibilitará uma outra leitura : aquela determinada pelo objeto de estudo".

Os termos utilizados para codificar as categorias emergiram dos discursos dos entrevistados. Foram eles o Objetivo da Observação, Significado da Observação, Características da Observação, Modo de Observar, Finalidades da Observação, Como se Preparou para Observar e Como Ensinar a Observar.

As citações foram registradas entre aspas, mostrando o pensamento individual de cada entrevistado, na seqüência em que ocorreram. 


\section{APRESENTAÇÃO E ANÁLISE DOS DADOS}

\section{Categoria - OBJETIVO da Observação}

Os enfermeiros entrevistados ressaltaram a importância de se observar, com o objetivo de levantar situações significativas que indicassem a necessidade de uma atuação profissional. Isto mostra a necessidade de terem uma capacidade discriminatória, no julgamento das situações que apontem uma possível intervenção.

HORTA $^{7}$ foi bastante clara ao indicar como objetivo da observação, o levantamento de dados como premissa fundamental para se estabelecer o diagnóstico de enfermagem. Devem ser entretanto, na sua opinião, coletados de maneira sistemática e cientificamente orientada.

Esta opinião foi reforçada por BYERS ${ }^{2}$, ao afirmar que o enfermeiro deve usar seu conhecimento e experiência, para estabelecer quando as observações sugerem a necessidade de intervenção de enfermagem.

A capacidade de fazer um julgamento correto, denota o preparo e a segurança do profissional de observar um fato, com um entendimento que permita fazer uma interpretação e reconhecer a significância dos dados colhidos.

"identificar situações que sejam, que tenham representatividade para o enfermeiro. De reciclar em tudo que se vê que é importante para o enfermeiro e que daí suscite uma possível intervenção, uma possível atuação do profissional (...) Então a visão do enfermeiro vai discernir nisto tudo o que é importante para o enfermeiro, o que ele pode trabalhar e o que ele não vai precisar."

"quanto de informações você já coleta para sua intervenção, pois é tudo direcionado para a intervenção. “

“estar conseguindo ver o paciente(...)porque paciente de UTI ele pode ao mesmo tempo em que ele está bem no momento, ele pode assim, ter intercorrências que no decorrer do seu período de permanência na unidade, então a gente tem em mente que ele pode estar bem, mas que ele pode vir a apresentar várias coisas, tipo as arritmias e mesmo uma parada cardíaca que pode acontecer(...)Então estar observando o ambiente, né? Como um todo".

Esta citação anterior também explicita um estado de "prontidão" necessário ao profissional, descrito por SUNDBERG $^{16}$, como o desenvolvimento de um $6^{\circ}$ sentido, na observação não planejada ou assistemática, que antecipa e prepara o enfermeiro para situações inesperadas. Esta "prontidão" também é citada por RUDIO $^{15}$, ao afirmar que ela mantém o profissional preparado e atento ao que pode acontecer.
KRON \& GRAY ${ }^{9}$, chamam de $6^{\circ}$ sentido a intuição, que é obtida através do conhecimento e comprensão de fatos adquiridos, como produto de experiências em situações semelhantes, devendo ser cultivada e não ignorada.

A busca da qualidade da assistência de enfermagem como objetivo, foi demonstrada em algumas citações, evidenciando a preocupação dos profissionais em prestar um atendimento qualificado:

"... com o objetivo maior de oferecer uma melhor assistência, realmente assistência de boa qualidade."

“...principalmente verificar se as ações que a gente está prestando estão tendo algum efeito."

Quando o objetivo é qualidade, o profissional se vale de métodos de trabalho, planeja seu atendimento e faz a avaliação do resultado. Ele observa ao planejar, faz julgamento crítico para agir, sua ação e o resultado da atuação. Tudo isto engloba a avaliação e qualidade do cuidar.

\section{Categoria SIGNIFICADO da Observação}

O significado da observação foi identificado nas citações, quando os entrevistados a consideraram como um instrumento fundamental na enfermagem, que permite a coleta de dados significantes para a intervenção profissional.

A observação foi assim também considerada por HORTA $^{8}$, como instrumento básico da enfermagem, juntamente com outros 9 que são - comunicação, avaliação, destreza manual, aplicação de princípios científicos, planejamento, criatividade, trabalho em equipe, método científico e encaminhamento aos recursos da comunidade. Esta autora assim os chamou, por considerá-los o "conjunto de habilidades, conhecimentos fundamentais para o exercício de todas atividades profissionais".

" é um instrumento de trabalho que a gente tem, fundamental (...) para o próprio desempenho da profissão."

"A observação tem dois significados centrais e um colateral. O $1^{\circ}$ significado central é aquele que a gente aprende na disciplina de fundamentos como instrumento básico de enfermagem. Observar é uma maneira de você colher dados para você poder deflagrar sua prática. Num $1^{\circ}$ momento é um instrumento que te permite aproximar da realidade e em cima disso você conseguir definir uma ação..."

"a observação é um instrumento mesmo, onde eu me sirvo dele para estar coletando dados..."

"eu entendo a observação como um instrumento, assim como a comunicação (...) é um instrumento que você tem para desenvolver sua assistência em várias etapas..." 
"significa identificar dados e acontecimentos que tenham importância no contexto do paciente."

Além do significado de instrumento, a observação também foi considerada como forma de controle, fiscalização, e avaliação do desempenho profissional.

"Uma $2^{a}$ coisa que é forte na formação do enfermeiro, é observar como uma forma de controle, no sentido de fiscalizar, no sentido de estar vendo o que o outro está fazendo, de também o observar no sentido mais amplo da palavra, que é cumprir determinados comportamentos já definidos como corretos."

"olhar ao desempenho dos auxiliares que estão subordinados a outros enfermeiros, como eles desempenham suas atividades (...) Se você está olhando o desenvolvimento de alguma técnica(...) então é olhar como esta técnica está sendo realizada, como está sendo a resposta do paciente frente a esta técnica(...) observação direta, acompanhar como ele faz um controle, como ele prepara a medicação, como ele faz um curativo."

MENDES ${ }^{11}$ considera que a observação funciona como instrumento objetivo de medição qualitativa e quantitativa do trabalho na enfermagem. CARVALHO ${ }^{3}$, considera como um "instrumento de controle, avaliação e validação de resultados obtidos para identificação e solução de problemas de enfermagem".

A observação é necessária à supervisão, fornecendo informações sobre o paciente, ambiente, equipe e atendimento prestado. Desta forma permite determinar a eficácia da assistência de enfermagem proporcionada, na medida em que permite atentar para o desempenho da equipe e para o próprio paciente, durante e após o atendimento de enfermagem. Pode ser usada para guiar, ajudar e estimular a equipe.

Outro ponto levantado pelos enfermeiros, foi a possibilidade de se estabelecer vínculo com o paciente, família, equipe, e aluno como forma de interação que aumentaria a eficácia do tratamento e facilitaria o trabalho da enfermagem, sendo até considerado como "base do cuidado".

Este aspecto lembra que antes de agir, o profissional estabelece uma relação de confiança com o paciente/família e mesmo dentro da equipe de trabalho ou com um aluno; muitas vezes isso ocorre através de comunicação não verbal, que é muito forte, e envolve a compreensão do outro com quem se convive, como pessoa que possui emoções, atitudes e diferenças individuais. Essa consideração facilita o trabalho, leva a um espírito de cooperação entre todos os envolvidos. Consegue-se um atendimento qualificado, associado à satisfação pessoal do paciente e equipe.

"a observação é um conjunto de fatores, relacionados ao paciente, à família (...)o que me chama mais atenção na observação e na minha opinião é a base do cuidado, realmente, daí é que acaba emergindo todos os fatores, é em relação ao vínculo, né? Da mãe ou do pai , no caso vínculo pais-filho, e também em relação aos profissionais da área (...) é interessante, você percebe que o tratamento, na verdade, ele se torna mais eficaz na medida em que os pais se tornem mais seguros, em relação aos profissionais que the dêem atenção, uma palavra de confiança."

"A $3^{a}$ vertente, é o observar como forma de interagir com outra pessoa. Então eu observo o outro para compreendê-lo e estabelecer uma relação (...) não só pela atitude de observar que vai demonstrar que eu tenho algum interesse naquele outro, mas também ao compreender o que o outro faz, estar mais preparada para estabelecer uma relação, seja com outro profissional, seja com um paciente, e com o aluno numa situação de ensino-aprendizagem (...) No meu local de trabalho, é muito valorizado esta observação para estabelecer relações, acaba assumindo um papel maior. Primeiro você observa, estabelece um contato não verbal, depois você vai querer saber quem ele é, o que está fazendo ali."

Ainda como significado da observação, foi identificada nas citações a capacidade de criar o que foi chamado de "olho clínico", que é perceber além do óbvio; captar, apreender o que as situações mostram.

"tem que olhar para as pessoas e sacar, tentar entender nas entrelinhas o que que é(...)desenvolver essa habilidade de observar, é criar o olho clínico. É você bater o olho num paciente e perceber uma série de coisas sem ele te dizer nada, ou até ele te dizendo alguma coisa, é você tentar entender nas entrelinhas pela da observação da expressão, do jeito que ele está, de como ele se comunica, se comporta, de como ele anda, né?(...)Ter capacidade de criar o olho clínico, de perceber além daquilo que ele está vendo, que é óbvio. É o famoso não verbal."

"ato de você olhar, direcionar teu olhar para alguma coisa ou objeto que pode ser uma pessoa, e você tentar apreender através da sua visão, sobretudo, aquilo que esse objeto apresenta para você. Então, para mim, do ponto de vista bem conceitual, a observação é esse ato de olhar, dirigir esse olhar para alguma coisa, e tentar apreender o que essa coisa, esse objeto mostra para você."

Em um dos relatos foi colocado que a observação está inserida em um processo de conotação mais ampla que seu conceito pode mostrar. Foi assim também considerada por CARVALHO ${ }^{3}$, ao afirmar que há um processo de observação que inclui a observação sistemática (reconhecimento de sinais e sintomas), a inferência clínica (julgamento) e a tomada de decisão (prioridades de enfermagem a serem prestadas). 
"Do ponto de vista da enfermagem, acho que tem um caráter diferente essa observação, talvez assim numa conceituação mais abrangente dentro de um processo, já que ela é um instrumento para a gente, mas mesmo estando inserida dentro de um processo, a base dela repousa nessa coisa que eu chamei de simplista. Na enfermagem ela tem um caráter mais abrangente(...) $\mathrm{Na}$ enfermagem tem conotação muito mais ampla, mais abrangente, mas do ponto de vista conceitual é muito simples."

\section{Categoria - CARACTERÍSTICAS da Observação}

As características da observação foram levantadas em um discurso quando afirmado que ela necessita um planejamento, objetivo, registro, deve possibilitar verificação posterior, e o observador ter claro um referencial teórico que norteie sua observação. Para este profissional, o "olhar próprio" muda a característica do que se olha, e envolve a vivência e potencial de cada um.

"Envolve um planejamento, envolve um objetivo, envolve um registro, envolve a possibilidade de ser possivel verificação posterior, então que envolve estas características que vão além do perceber, mas eu acho que o básico da observação, é você ter clareza de um referencial que faz com que você olhe um determinado objeto(...) se eu tivesse que valorizar uma característica de observação, além de falar que ela é possível sim, de ser verificada por outro, que ela tem que ter essa característica do registro, de ter nome as coisas que você percebe, de você ser capaz de nominar, de você planejar o que vai verificar, e nesse planejamento envolve a clareza de um referencial teórico(...) Que o fato de você estar olhando para uma coisa, já muda a característica dessa coisa, no sentido de que seu olhar já é próprio de você. Já envolve a sua experiência, já envolve seu tato, seu referencial teórico. Então é na verdade a sua capacidade, sua potencialidade, que vai definir o próprio objeto(...)se eu tivesse que escolher uma característica para falar de observação, eu diria que é você ter a clareza de qual éo seu referencial ao olhar."

Muitas vezes ao fazer uma observação, os fatos registrados necessitam de uma conclusão, ou seja uma inferência, e para que isto ocorra, vai depender do conhecimento científico (baseado nas ciências sociais, naturais, biológicas e do comportamento) e da segurança do observador, para que se obtenha o entendimento do que se observa, e para saber quando sugerem desvios que requerem auxílio.

Pode também, como afirmou o relato acima, depender do referencial adotado por ele, pois todos têm pré-conceitos a respeito de tudo que os cerca, adquiridos com o passar do tempo, ainda que não conscientes. Quando este referencial é construído, serve de guia ao observador, mas deve ser também claro a quem lê o registro.

A ausência de registro impossibilita que os fatos sejam conhecidos em detalhes e na ordem que se deram.

$\mathrm{O}$ registro permite que as informações sejam partilhadas dando o sentido da continuidade do serviço prestado, de forma que a associação de fatos possa clarear uma ocorrência. Devem ser entretanto objetivas, livre de opiniões ou preconceitos pessoais. O perigo da subjetividade está em ser de interpretação individual, que pode não corresponder à realidade, além do que, o estado de espírito do observador pode intensificar a percepção seletiva dos fatos. Esta é uma habilidade que o enfermeiro deve refinar, com maturidade e autodisciplina, mas que só é conseguida com aquisição de conhecimento específico e experiência em fazê-lo continuamente. A riqueza de detalhes vai depender do grau de treinamento do observador.

É o registro que permite que uma ocorrência seja verificada quando reincidente, ou quando mostra uma mudança no quadro do paciente, podendo ser consultado por outros profissionais.

Permite também uma avaliação da interpretação e conduta do profissional, podendo ser verificada sua efetividade. O uso das palavras adequadas é, então, essencial.

\section{Categoria - MODO de Observar}

Ao descrever a forma de observar, os entrevistados citaram várias vezes o "olhar atentamente", o "olhar e ver alguma coisa". Esse olhar com atenção não ficou restrito ao sentido da visão, sendo citada a utilização dos demais sentidos, para captar, perceber o paciente, seu ambiente e real estado de saúde.

Apenas um profissional explicitou a quais sentidos se referia (visão, tato, olfato), excluiu o paladar, e não mencionou a audição. Outro profissional se referiu especificamente à visão e ao tato.

$O$ relato que exclui o uso do paladar na observação, o fez da mesma forma que BYERS ${ }^{2}$, contradizendo o que McCLAIN \& GRAGG ${ }^{10}$ afirmaram - "a enfermeira conhecendo o sabor dos vários alimentos e medicamentos pode avaliar se o paladar do paciente é normal".

SUNDBERG $^{16}$, citou a observação como "receber informação através dos sentidos", e identificou os cinco (audição, visão, tato, olfato e gustação). Outros autores citados neste estudo $^{6,13,15}$ fazem referência ao uso dos sentidos, sem entretanto, nomeá-los.

$\mathrm{O}$ uso dos sentidos deve ser feito de forma consciente, intencional, guiada por um conhecimento 
científico do profissional, num trabalho equilibrado de todos os sentidos e da razão.

O perceber citado por alguns entrevistados, na opinião de BYERS ${ }^{2}$, é mais que o ver - "é entender o que é detectado através dos sentidos".

"é olhar atentamente para alguma coisa."

"é olhar atentamente ao paciente(...) é olhar procurando alguma coisa.(...) é ficar atento ao que está em volta de você, e principalmente o que diz respeito à assistência de enfermagem ao paciente(...) é você olhar e ver alguma coisa."

"é um olhar atentivo para o paciente, é você olhar atentamente para o paciente (...) Olhar atentivamente para o paciente procurando assim, vê-lo como um todo, ne'? Até mais daquilo que os sentidos podem captar, né? (...) observar olhando assim atentivamente, procurando entender o não verbal, aquilo que o paciente não fala, mas que ele demonstra, né? (...) você observa a parte biológica, mas mais no sentido de tentar compreender, entender aquilo que o paciente representa. Então o medo, a preocupação, embora ele não verbalize isso. Na maioria das vezes ele não verbaliza, o medo da punção, principalmente o adulto. Embora não verbalize, ele demonstra isso com suas atitudes(...) procurar compreender, avaliar o paciente neste todo, não só naquilo que ele diz, mas principalmente naquilo que ele não diz, né, naquilo que ele demonstra através dos seus comportamentos, do não verbal mesmo(...) minha observação é dirigida não só pelo aspecto biológico(...) mas no sentido de como ele vai chegar, do seu estado psicológico, emocional; tudo isto vai influir no resultado cirúrgico".

"Quando eu estou falando olhe, eu não estou falando só olhe de visão, eu estou falando olhe no sentido de observação, então você pode olhar um objeto através do tato, né?"

"Você começa a sacar as pessoas, a perceber a leitura que o corpo está te dando. Quem não está treinado não percebe".

"Eu disse do olhar, principalmente, porque eu acho que passa por isso, mas sem descartar a questão dos outros órgãos do sentido. Eu acho que o tato, no momento da observação, é menos utilizado. Mas você tem a coisa da observação que vem do olhar, mas que vem do cheiro também, né? O tato fica meio de lado, o paladar fica totalmente de lado, mas acho que é o olhar, sobretudo (...) numa simples observada que você dá no paciente, quanto de informações você já coleta”.

Além da necessidade de se usar todos os sentidos para se obter informações da realidade, fica claro nas entrevistas acima citadas, que a observação supera aquilo que eles captam, vai além do que o paciente fala; é o uso da comunicação não verbal que o profissional deve aprender a fazer uso.
A postura do paciente, sua expressão facial, suas atitudes, geralmente mostram seu pensamento, seus valores, crenças e emoções. Os comportamentos podem ser compreendidos, se o enfermeiro aprender sua linguagem ${ }^{9}$.

Outro ponto levantado nas entrevistas sobre o modo de observar, é a respeito da necessidade de observação do ambiente.

“...você olha a unidade e a todo instante você está tendo novas informações que podem te ajudar; algumas têm importância outras não...."

"a observação é estar tentando enxergar a UTI como um todo, né? Você conseguir separar paciente por paciente, estar sabendo o que é cada um(...) para observar, primeiro eu olho num box de um paciente e tenho que ver tudo que ele está precisando no momento e o que ele pode vir a precisar também, né?(...) você estar vendo não só o paciente, como a unidade em que você está trabalhando. A observação nada mais é que você estar olhando mesmo, né? E saber distingüir diferenças das intercorrências..."

A observação do ambiente permite detectar riscos e necessidades atuais ou potenciais para o paciente, assim como fatores que possam melhorar seu bem estar. O ambiente em que se encontra, pode influenciar no restabelecimento do paciente e auxiliar na percepção do seu real estado. Na opinião de SUNDBERG ${ }^{16}$, a observação inclui o paciente e seu ambiente.

A observação deve ser feita de forma sistemática, planejada, com objetivo determinado, sabendo o que se está procurando. Isto pode ser evidenciado nas seguintes citações:

"Estou dizendo um olhar no sentido mais amplo de estar atento a, de forma planejada, né?"

"Profissionalmente, é olhar com algum objetivo(...)se você tem um objetivo, você vai observar com maior atenção, ver minuciosamente alguma coisa, porque quando eu penso em observar de uma forma geral sem ter algum objetivo, você pode estar olhando basicamente uma série de coisas, mas quando você tem um objetivo, vai olhar mais minuciosamente para algo, ou vai procurar, ou vai ver detalhadamente aquela coisa para encontrar ou para afirmar que não existe."

Estes relatos confirmam o que afirmou HEGENBERG' ${ }^{6}$, de que a observação " não é um exame casual, mas uma busca intencional, ordenada, não com o intuito de colecionar dados, mas para encontrar neles alguma ordenação".

Na observação sistemática nada é destituído de valor; o comum, normal, é levado em consideração, e não só o incomum, pois pode fornecer dados que confirmem ou rejeitem o significado de um fato.

O profissional deve saber o que procurar, quando procurar e o que fazer quando achar. A observação não é 
mera contemplação de fatos, e sim uma busca proposital.

Houve uma das afirmações dos entrevistados que se referiu ao momento de se observar, que não seria somente durante a entrevista, e sim durante todo o cuidado prestado ao paciente.

Isto foi levantado por BYERS ${ }^{2}$, ao afirmar que os problemas são melhor observados de forma indireta, coincidindo com os cuidados. É estabelecida uma relação de confiança, sendo ótima oportunidade para se ouvir o paciente, mesmo quando o enfermeiro não está prestando cuidado físico.

"eu acho que a observação não é só feita no momento da entrevista, mas no cuidado todo eu me utilizo dela, para estar sabendo o que o meu paciente está sentindo, está expressando através do não verbal, o que esse não verbal está me dizendo, o que o verbal está me dizendo, e observações mais concretas."

\section{Categoria - FINALIDADE da Observação}

Uma das finalidades identificadas nos relatos é a possibilidade de verificar a efetividade da assistência prestada ao paciente, através da observação de sua resposta ao tratamento.

"é através dele que a gente verifica como está sendo feita a assistência de enfermagem, como ela poderia ser melhorada, como está sendo a resposta do paciente, se realmente está tendo uma resposta esperada(...)atento principalmente ao que diz respeito à assistência de enfermagem ao paciente, e como é a resposta do paciente em relação à assistência de enfermagem recebida..."

"Pela observação eu sei se o que eu estou fazendo está dando certo ou não, se o paciente está gostando ou não, e também muitos dados são coletados para eu administrar a assistência."

"Com a observação você tá vendo este tipo de coisa, né? Se ele está com uma determinada droga, ele está fazendo arritmia, você tem que associar, este tipo de coisa, né? Se aquela droga que ele está recebendo está a mais ou a menos, você tá vendo um monte de coisa, tá vendo freqüência cardíaca, você está vendo pressão, então você está observando aquilo, você tem que correlacionar também né? O paciente, se ele está respondendo às expectativas, né?"

CARVALHO $^{3}$ foi clara ao colocar a observação como forma de validar resultados obtidos, concordando com os entrevistados. Isto vai de encontro às propostas de trabalho da NANDA(North American Nursing Diagnosis Association) com diagnóstico de enfermagem, que utiliza as respostas humanas como referência para o julgamento clínico, onde se baseiam as intervenções de enfermagem.

Outro aspecto levantado pelos entrevistados, identificado como finalidade da observação, é a sua utilização para se padronizar as condutas de um grupo a partir das observações de cada um, sobre como está a assistência de enfermagem.

"Cada um fala o que acha importante mudar. Assim a gente vai padronizando nossas condutas e está muito relacionado com a observação, porque essa padronização surge da observação de todos enfermeiros. Eu, como líder do grupo tenho que ficar atenta ao desempenho de cada profissional, inclusive dos enfermeiros. Muitas vezes a idéia parte de mim, e outras de alguma colega. O grupo acha que alguma coisa poderia ser melhor, porque observou que alguma coisa não está adequada. Então a gente senta e discute. Algumas vezes partiu de mim, porque vi o desempenho de uma colega ou de várias colegas sobre determinada coisa que talvez não fosse a forma mais adequada. A gente senta, discute e chega a um consenso de forma que melhore a nossa assistência de enfermagem."

Este seria então um momento de partilha, no qual cada um identifica problemas e sugere soluções. Para a chefia é também o momento de apoiar, orientar e sugerir alterações na administração da assistência de enfermagem. A liderança compartilhada faz com que cada um se sinta responsável pelo sucesso do todo.

Há de se considerar que é o momento ideal para a educação continuada do profissional, tão subestimada na nossa prática. Estas discussões conduzem a ações mais uniformes da equipe.

Foi salientado também por alguns enfermeiros sua utilidade como instrumento de orientação de alunos para a coleta de dados, e para se aprender a fazer um bom exame físico, um levantamento completo de informações.

"serve como instrumento para eu estar orientando meus alunos a estarem coletando dados desse paciente, para que ele possa fazer o planejamento."

"uma pessoa só consegue fazer um bom exame físico, uma coleta de dados completa, a partir do momento que ele é um bom observador."

"Na enfermagem ela tem um caráter mais abrangente, na medida em que ela é parte de um todo que você vai estar utilizando sobretudo para você estar tendo uma coleta de dados, informações que você pode estar levantando para depois você poder ter uma intervenção de enfermagem, que vai ser pautada em dados que você levantou não só da observação, mas também por meio dela."

Enquanto para uns é um instrumento de coleta de dados, para SUNDBERG ${ }^{16}$ faz parte de um método de coleta de dados, juntamente com a interação pessoal e o exame físico.

Outro ponto enfatizado por um profissional, é a 
utilização da observação como forma de agilizar o serviço de enfermagem, quando há sobrecarga de trabalho que impede o levantamento de dados de forma adequada.

"No nosso sistema de saúde, de poucos profissionais, muitas vezes é da observação que a gente pode se valer, no meio de tantas outras coisas que se faz e te absorve, a ponto de não poder fazer um exame físico tão detalhado quanto gostaria, ou de ter um tempo maior para fazer uma entrevista e coletando dados como gostaria. A medida que você tem a observação desenvolvida você ganha muito”.

Esta colocação mostra o dia-a-dia de muitos profissionais, no nosso sistema de saúde, que se valem do que conseguem, como escudo de proteção da própria consciência profissional.

\section{Categoria - COMO SE PREPAROU para Observar}

Foi da opinião de alguns entrevistados que a escola fornece conceitos sobre observação, que são entretanto insuficientes e o que realmente os ensinou foi o tempo, a partir de experiências vividas; que a habilidade em observar é desenvolvida.

"eu acho que a escola dá alguns conceitos básicos(...) ela vai se desenvolvendo com o passar do tempo, quer dizer, o enfermeiro vai criando habilidades para observar".

"a gente aprende na escola os vários conceitos(...)a partir do dia a dia em que você está vivendo, vendo um monte de coisa(...)você consegue estar vendo várias coisas que antes era difícil, que antes você não consegue distingüir determinadas situações, como estudante ou como no início de uma carreira quando você chega num local, e mesmo assim agora a gente chega num local diferente, a gente tem dificuldades para estar se adaptando àquelas situações. Então é uma adaptação também que você tem para que você consiga ver um monte de coisa que uma rotina contém, que com o tempo de trabalho que você tem, você consegue estar vendo mais fácil, detectar determinados erros".

"a faculdade não nos prepara para a observação. Acho que ela nos dá uma orientação muito básica, mas isto se desenvolve com o passar do tempo (...)eu me lembro que até recebi esta orientação, mas eu acho que tem que ser mais explicado(...) com o passar do tempo e com a experiência, a observação, ela é desenvolvida, mas acho que a gente sai muito pouco preparada da faculdade para realmente estar observando as coisas. Acho que poderia ser melhor, mais voltada à pratica".

"Aprendi a observação dirigida na escola né, o que você tem que observar, quando você está iniciando com um paciente, quais são os parâmetros que você deve observar". "você fica entregue às suas próprias experiências, suas próprias vivências(...)Eu também não aprendi, e você aprende na prática, na coleção de experiências vividas. Um dia eu entrei, não vi alguma coisa, a supervisora me deu uma baita bronca e eu nunca mais vou esquecer que tem que olhar aquilo, né?"

"é nessa agilidade que você desenvolve para observar, que você consegue estar mais apta para dar conta das coisas que vão acontecendo no dia a dia...é muito de desenvolver, e cada um desenvolve essa observação da sua maneira, do seu ritmo".

Houve referência ao distanciamento do ensino teórico com a prática.

"houve o estímulo mas poderia ter sido maior. Então, acho que este estímulo tem que ser voltado a prática. Eu lembro que muito isto, inclusive em relação ao próprio tema, o que é observação, foi falado que a observação é importante para a enfermagem, mas fica fica longe da prática”.

Foi lembrado também que não foi percebida uma intenção por parte da escola em treinar o aluno de forma sistematizada para observar.

"Não há uma intenção em tornar você hábil no manejo deste instrumento(...) você não tem todo um treinamento sistematizado para se apropriar desse instrumento e tirar proveito dele. Isto não acontece, e eu não me sinto capaz de fazer isto com o aluno. Eu aprendi na raça e ensino assim".

Estas afirmações mostram bem que não foi percebida a importância do ato de observar durante a graduação. Só atentaram para isto quando da necessidade de sua utilização na profissão.

Este é um fato comum em vários assuntos na graduação, quando a escola não consegue que o aluno dê importância devida àquilo que ela aponta como essencial à profissão. É a consciência do desenvolver no aluno aquelas habilidades fundamentais ao enfermeiro, que não são de cunho meramente técnico. Muitas vezes, as escolas enfatizam a aquisição de conhecimento, dando pouca atenção ao grau de compreensão que o estudante adquire ou que realmente precisa.

O aluno por sua vez, não tem maturidade suficiente para dar ênfase a pontos cruciais para seu futuro trabalho, ou também não dá a devida atenção a assuntos que não consegue associar com sua prática, pois não refletiu sobre suas experiências acadêmicas. Ele não adquiriu a capacidade de colocar em prática o conhecimento adquirido, que significa na realidade a compreensão do assunto.

É citado por DIAS ${ }^{5}$, que a postura do profissional frente ao fundamento e utilização da observação não surge ao graduar-se; ela é resultante do relacionamento docente/ aluno durante os anos de estudo.

SUNDBERG $^{16}$ afirma que o conhecimento 
adquirido deve ser "internalizado" pelo enfermeiro, e que a medida em que cuida de pacientes, esta habilidade será refinada. Para este autor, a observação é uma habilidade vital, melhorada com treino e experiência.

Com o passar do tempo, aquela Capacidade (potencial para ação) que se processa durante toda a vida do indivíduo, desenvolve-se através da prática dirigida de observar, gerando a Habilidade (maneira pela qual este potencial se transforma) de reconhecer os fatos inerentes à profissão ${ }^{4}$.

Não foi possível deixar de notar nos relatos que, enquanto um enfermeiro sugere que se deve preparar o profissional, com estímulos voltados para a prática, outro sugere que continue assim, evidenciados em "o estímulo deve ser voltado para a prática" e em "eu aprendi na raça e ensino assim". Denota um certo conformismo com uma situação que ele próprio criticou.

\section{Categoria - COMO ENSINAR a Observar}

Algumas formas de ensinar a observação foram citadas por seis entrevistados, que levantaram pontos os quais acreditam serem essenciais para o aprendizado:

O ensino deve ser dirigido para a prática, mostrando o que é observar, e também fazer uso de roteiros que facilitem o trabalho do aluno.

"eu acho até que poderia ser melhor se a gente fosse mais estimulada durante a vida acadêmica para estar observando(...) o aluno quando se fala em observar ele tem que saber o que é observar(...)acho que este estímulo tem que ser voltado a prática(...)Então que o estímulo fosse mais relacionado assim, à nossa prática mesmo. No estágio : olha, observa isto, o que é observar isto?(...) Como vai ser a resposta do paciente? Como é que você espera que seja a resposta e observar como vai ser a resposta frente à assistência de enfermagem e frente a terapêutica médica".

"a observação para mim é algo que tem que ser estimulado no aluno, e embasada com dados mesmo concretos. Coisas que ele ainda não consegue ver, ele passa a ver a partir do momento em que você docente fala: E aí? Você observou aquilo? No começo até um roteiro de observação se faz necessário para que depois o aluno, com a competência, com dados mais concretos do conhecimento, ele possa a partir dali ter sua própria visão, e formular então as suas questões a respeito do que observa(...)eu me sirvo da orientação, e estimulo o aluno para que se sirva da observação. Eu acho que é um meio que acaba sendo seguro para esse aluno saber que caminho seguir no planejamento e na orientação”.

O conteúdo de uma matéria é melhor fixado, quando é feita uma associação com a realidade que evidencie sua utilidade. Além disso o uso de roteiros, diminui inicialmente a ansiedade dos alunos que percebem que há um direcionar do pensamento na busca de informações. Já dizia NIGHTINGALE" que "a lição prática mais importante que pode ser dada a enfermeiras é ensinar-lhes o que observar, como observar(...) é parte essencial do preparo".

Discutir a observação dentro do contexto da coleta de dados, como forma de sistematizar a assistência, de se ter método de trabalho.

"Nós não estamos mais dando observação como uma aula separada de algum contexto. Esta discussão de observação, de percepção, é contextualizada quando em fundamentação, discuto a coleta de dados. Porque a hora que ele vê que a forma de fazer enfermagem precisa ser sistematizada, que você pode fazer dessa forma meio maluca, desorganizada, porque o que você está fazendo é quebrar galho(...)o lógico é você ter algum método de trabalho. Aí a $1^{a}$ fase da discussão desse método de trabalho, é a coleta de dados. Na coleta de dados, especificamente na entrevista, antes do exame físico, a gente entra com essa discussão do perceber, do observar. Quando eu contextualizo a necessidade de você fazer o atendimento de enfermagem de forma sistematizada, falar o que é estar atento a, o que é observação, porque eu preciso nominar, porque eu preciso planejar".

$\mathrm{O}$ aluno deve perceber que a observação não se desenvolve isolada. Ela faz parte de um plano maior que é o assistir, e como tal serve de apoio para outros instrumentos. Há uma organização que transcende a mera constatação de dados, que deve ser evidenciada pelo estudante, na busca de um atendimento individualizado. O planejamento e a organização asseguram que os objetivos sejam atingidos.

O professor fornece pistas para que o aluno observe, que facilitará sua observação. Não propriamente "ensina a observar".

"Ele vai perceber que ele pode ter algumas pistas para facilitar essa observação. Tenho alguns detalhes que o paciente pode apresentar, e que são pistas que ele pode estar procurando. Então isto facilita, não que eu vá ensinar a observar. Você vai dar pistas para o que observar. Como observar, a atenção dele para observar, eu acho que eu não consigo ensinar. Eu dou pistas para ele do que observar. Ele vai procurar por isto. Se for algum determinado sinal, eu posso ensinar para como ele pode perceber esse sinal no paciente".

As pistas são essenciais ao aluno, pois mostram o caminho a seguir, mas ele precisa mais que isto. Necessita ter claro o porque observar, como e quando fazê-lo. Esta orientação pode acelerar o desenvolvimento de sua capacidade de observar. Cada um introjeta o conhecimento de forma diferente, mas pode ser facilitado pelo professor.

Deve ser tentado despertar no aluno um "estado de alerta" conseguido com a observação. 
"está faltando no aluno aquela prontidão, para ver outras coisas que não aquele exame físico céfalocaudal bem sistematizado(...)aquela coisa mais ágil, que eu acho que é a observação que ele vai te dar(...)treinávamos o olhar. Era um olhar clínico, mas também para apreender esse paciente bem. Então, acho que a observação, a gente usa muito na enfermagem, tem essa preocupação em estar desenvolvendo no aluno, para que ele possa ter até mesmo essa prontidão em termos de algumas coisas que são mais ágeis, dependendo da situação. Acho que a gente ainda não achou a forma ideal de fazer isso...acho que nós, enquanto formação tem que estar atenta para despertar nele essa prontidão”.

A percepção daquilo que foge ao padrão é essencial, visto que os pacientes têm sua individualidade que deve ser caracterizada pelo profissional. A agilidade em perceber o observado é desenvolvida com o tempo, mas o aluno deve ser dirigido a isto.

É uma arma do enfermeiro que deve ser desenvolvida no aluno. Deve aprender a observar de forma sistematizada, percebendo além do que é falado pelo paciente. A qualidade da assistência irá melhorar a medida em que for desenvolvida a habilidade em observar.

" A observação que eu levo, que eu espero que eu procuro dirigir, para o meu aluno desenvolver, é um instrumento, uma arma poderosa do enfermeiro, e ele tem que aprender a observar sacando as coisas. Ele tem que olhar para as pessoas e sacar, tentar entender nas entrelinhas o que que é. Eu falo para eles, que eles desenvolvem este tipo de habilidade no convívio com amigos. Sem o amigo falar nada você sabe se ele está alegre ou triste. Porque você já está em sintonia, você já entende o tipo de olhar, o jeito. Este tipo de habilidade, essa sagacidade, ele tem que desenvolver em relação ao paciente(...) É nesse sentido que eu oriento o aluno. Que ele precisa desenvolver essa habilidade, uma observação sistematizada. Não é olhar e passar direto; ele tem que olhar e se fixar no que ele está acontecendo. Isso só se desenvolve com muito treino, é um instrumento poderoso que ele tem, e eu digo que ele tem que criar o olho clínico. Ele tem que olhar e perceber que daqui a pouco ele vai piorar, que a tendencia é agravar, que o paciente está angustiado. Isto tudo ele só vai conseguir pela observação. Acredito que essa é uma habilidade que o aluno pode desenvolver, ele pode levar para a vida profissional e continuar desenvolvendo(...) Digo que a otimização da assistência se dá, na medida em que você desenvolve muitas vezes coisas que não te são pedidas. Como é o caso de vocêfazer uma boa comunicação, saber fazer uma boa abordagem. Tem várias formas de falar bom dia, ou boa tarde(...) a sua assistência vai melhorar de qualidade à medida em que você desenvolve essa habilidade de comunicação, de observação. Neste sentido é responsabilidade de cada um. Eu sempre coloco que é uma coisa que os alunos devem treinar, é uma capacidade que o enfermeiro deve ter, porque ele não é enfermeiro só no hospital".

A percepção dos fatos em sua espontaneidade é muito rica, pois não é cerceada por algo dirigido, como ocorre ao se fazer uma pergunta ao paciente. A habilidade em observar deve ser apontada não apenas como uma técnica, mas deve levar o aluno a desenvolver processos mentais que elevarão sua percepção, com consciência da intenção do que faz.

\section{CONSIDERAÇÕES FINAIS}

A realização deste estudo permitiu evidenciar que os enfermeiros têm uma visão clara do que é observação, e a consideram de suma importância para sua atuação profissional.

Levantaram como objetivos da observação, a identificação de situações significantes que indicam a necessidade de atuação do profissional, e a busca da avaliação para análise da qualidade do atendimento ao paciente. Caracteriza um instrumento fundamental para coleta de dados, é uma forma de controle, fiscalização e avaliação de desempenho do enfermeiro, assim como, significa estabelecer vínculo como forma de interação entre o profissional/paciente/família e aluno, como base do cuidado, estando inserida num amplo processo de atendimento ao outro.

Indicaram como características da observação a necessidade de planejamento, de objetivos estabelecidos, de ter registro que permita verificação posterior, e de um referencial teórico que oriente a ação do enfermeiro. Como finalidade, indicaram a verificação da assistência prestada através da resposta do paciente, a possibilidade de estabelecer padronização de condutas de enfermagem, a orientação de alunos na coleta de dados, para se aprender a fazer bom exame físico e um levantamento completo de informações, assim como agilizar o serviço de enfermagem.

O preparo de cada profissional para observar, se deu com a prática, apesar de terem recebido alguma orientação na escola. Acreditam que deve ser estimulada no estudante de forma clara, com uso de roteiros e demonstrada sua necessidade para uma atuação sistematizada do enfermeiro na prestação da assistência ao ser humano.

Da mesma forma que DIAS ${ }^{5}$, foi evidenciada uma variedade de significados atribuídos à observação. Foram eles, instrumento, método de coleta de dados, processo, habilidade e capacidade. 
Os profissionais demonstraram conhecimento e competência para observar. Apesar de não terem sido preparados, tiveram consciência de sua limitação e buscaram desenvolver a habilidade.

Não foi entretanto citada, a utilização da observação na pesquisa. Os relatos foram centrados no ensino e na assistência.

Outro ponto digno de nota, foi a não referência dos entrevistados à observação, dentro da Metodologia de Assistência de Enfermagem, como fundamental para a continuidade do serviço. A ênfase foi sempre de registro para planejar assistência, não necessariamente como suporte para a atuação da equipe.
Com este estudo, foi possível caracterizar a observação na enfermagem, como a habilidade de entender de forma consciente as informações buscadas através dos sentidos (visão, tato, olfato, audição, gustação), desenvolvidas com treino e experiência, a partir da capacidade (potencial para ação) humana inata de observar e da existência de conhecimentos e competência nas ciências sociais, biológicas, naturais e do comportamento humano. Deve ser formulada, planejada e registrada de forma sistemática, com linguagem clara, objetiva, desprovida de opiniões, interpretações e preconceitos pessoais.

\section{WHAT NURSES SAY ABOUT OBSERVATION}

The purpose of this study was to characterize what faculty and clinical nurses understand about Observation at their professional activities. Eleven nurses were interviewed, and the data were joined in categories in order to be analized. It was possible to realize that they regard it with extreme importance at their professional activities, as an essential instrument of nursing care administration, assessment, planning interventions and evaluating results.

KEY WORDS: observation, nursing, nursing basic instrument

\section{LO QUE DICEN LOS ENFERMEROS SOBRE OBSERVACIÓN}

Este estudio tuvo como objetivo caracterizar lo que los enfermeros docentes y asistenciales entienden por Observación en su ámbito profesional. Fueron realizadas entrevistas con once profesionales, para analizar los datos fueron agrupados en categorías. Fue posible identificar la importancia que le atribuyen como instrumento escencial en la administración de la asistencia de enfermería, en la obtención de datos para planear las intervenciones, asi como en la evaluación de los resultados.

TÉRMINOS CLAVES: observación, enfermería, instrumento básico de enfermería

\section{REFERÊNCIAS BIBLIOGRÁFICAS}

01. BERELSON, B. Content analysis. In: LINDSEY, G. (org.) Handbook of social psychology. Massachusetts: Addison-Wesley, 1951. v.1, p.489.

02. BYERS, B.V. Nursing observation. 3.ed. Iowa: Library of Congress, 1970.

03. CARVALHO, V. Dos princípios e proposições da observação sistematizada na Enfermagem. Rev. Bras. Enfermagem, v.24, n.5, p.30-46, 1971.

04. DANIEL, L.F. A Enfermagem planejada. 3.ed. São Paulo: EPU, 1981.

05. DIAS, C.B.G. Observação em Enfermagem: a necessidade de um conceito. Ribeirão Preto,1990. 101p. Dissertação (Mestrado) - Escola de Enfermagem de Ribeirão Preto, Universidade de São Paulo.

06. HEGENBERG, L. Etapas da investigação científica: observação, medida, indução. São Paulo: EPU, 1976.
07. HORTA, W.A. Observação sistematizada na identificação dos problemas de Enfermagem em seus aspectos físicos. Rio de Janeiro, 1968. Tese (Livre Docência) - Escola de Enfermagem Ana Néri.

08. Editorial dos Instrumentos Básicos de Enfermagem. Rev. Esc. Enfermagem USP, v.4, n.1-2, p.3-4, mar-set. 1970.

09. KRON, T. ; GRAY, A. Administração dos cuidados de Enfermagem ao paciente. 6.ed. Rio de Janeiro: Interlivros, 1994.

10. McClaIn, M.E.; GRAGG, S.H. Principios científicos da Enfermagem. 2.ed. Rio de Janeiro: Científica, 1970.

11. MENDES, D. Observação. Rev. Bras. Enfermagem, v.36, n.1, 1983.

12. NIGHTINGALE, F. Notas sobre Enfermagem: o que é e o que não é. São Paulo: Cortez, 1989.

13. NOGUEIRA, O. Pesquisa social: introdução às suas técnicas. 3.ed. São Paulo: Nacional, 1975.

14. ROSEMBERG, F. Da intimidade aos quiprocós: uma discussão em torno da análise de conteúdo. Cad. CERU, São Paulo, n.16, novembro, 1981. 
O que dizem...

Rev. latino-am. enfermagem - Ribeirão Preto - v. 5 - n. 3 - p. 83-94 - julho $1997 \quad 94$

15. RUDIO, F.V. Introdução ao projeto de pesquisa científica. 8.ed. Petrópolis: Vozes, 1983.
16. SUNDBERG, M.C. Fundamentals of nursing with clinical procedures. 2.ed. Boston: Library of Congress, 1989. 